\title{
INFLUENCIA DE HABITOS ALIMENTARIOS SOBRE LAS CONCENTRACIONES DE PESTICIDAS ORGANOCLORADOS EN TEJIDO ADIPOSO ${ }^{1}$
}

\author{
Ijoni COSTABEBER ${ }^{2,3, *}$, Tatiana EMANUELLI ${ }^{2}$
}

\begin{abstract}
RESUMEN
Fueron evaluados los niveles de residuos de pesticidas organoclorados (p,p'-DDE, HCB, $\gamma$-HCH, aldrin) presentes en 123 muestras de tejido adiposo mamario obtenidas de mujeres residentes en Córdoba (España). Además, se investigó la influencia de hábitos alimentarios y edad de las donantes sobre los niveles de organoclorados encontrados en el tejido. El p,p'-DDE fue el compuesto encontrado en concentraciones más altas $(1,848 \mu \mathrm{g} / \mathrm{g})$, seguido de $\mathrm{HCB}(0,235 \mathrm{mg} / \mathrm{g})$, aldrin $(0,005 \mu \mathrm{g} / \mathrm{g})$ y $\gamma$-HCH $(0,003 \mu \mathrm{g} / \mathrm{g})$. Las donantes mayores presentaron niveles de p,p'-DDE, aldrín y HCB superiores que las más jóvenes. Sin embargo, la edad no influyó en los niveles de $\gamma$-HCH. La mayoria de las donantes $(40,65 \%)$ indicaron las frutas como el alimento más consumido, seguido de la alimentación variada (34,15\%), los legumbres $(6,50 \%)$, los guisos y potajes $(6,50 \%)$, las verduras $(4,88 \%)$, la leche $(3,25 \%)$, el pescado $(2,44 \%)$ y la carne $(1,63 \%)$. Una correlación no significativa fue observada entre los niveles de organoclorados en el tejido adiposo y los hábitos alimentarios de las donantes.
\end{abstract}

Palabras-clave: tejido adiposo; pesticidas organoclorados; habitos alimentarios; edad.

\section{SUMMARY}

INFLUENCE OF ALIMENTARY HABITS ON ORGANOCHLORINE CONCENTRATIONS IN ADIPOSE TISSUE.The levels of organochlorine pesticide residues (p,p'-DDE, $\mathrm{HCB}, \boldsymbol{\gamma}-\mathrm{HCH}$, aldrin) present in adipose tissue samples from mammary glands of 123 women living in Cordoba (Spain) were evaluated. The influence of alimentary habits and age of donors on organochlorine tissue levels was also investigated. The compound found at the highest concentration was p,p'-DDE $(1.848 \mu \mathrm{g} / \mathrm{g})$, followed by HCB $(0.235 \mu \mathrm{g} / \mathrm{g})$, aldrin $(0.005 \mu \mathrm{g} / \mathrm{g})$ and $\gamma$ $\mathrm{HCH}(0.003 \mathrm{mg} / \mathrm{g})$. The older donors presented tissue levels of p,p'-DDE, aldrin and HCB higher than those found in younger donors. Conversely, age had no influence on tissue levels of $\gamma-\mathrm{HCH}$. The majority of donors $(40.65 \%)$ indicated fruits as the most consumed food, followed by mixed food $(34.15 \%)$, non-green vegetables $(6.50 \%)$, stewed meat and vegetables $(6.50 \%)$, green vegetables $(4.88 \%)$, milk $(3.25 \%)$, fish $(2.44 \%)$ and meat $(1.63 \%)$. No significant correlation was observed between organochlorine tissue levels and the alimentary habits of donors.

Keywords: adipose tissue; organochlorine pesticides; alimentary habits; age.

\section{1 - INTRODUCCION}

En las últimas décadas, las cosechas de productos alimenticios han experimentado un aumento considerable. Ello ha sido posible, en gran parte, al resultado obtenido en la lucha contra las plagas que los deterioraban y, es innegable que los pesticidas han desempeñado en la misma un papel importante. Sin embargo, la aplicación de estas sustancias de forma intensiva, trajo como consecuencia que una parte de las mismas persistiera en el medio ambiente, conservando sus propiedades activas $\mathrm{y}$, más aún, que pasaran a organismos superiores. Por lo tanto, los pesticidas organoclorados, dada su especial característica de persistencia en el medio y el riesgo de su toxicidad crónica en el hombre, por acumulación de pequeñas cantidades que pasan de unos seres a otros y se concentran a través de la cadena alimentaria, representan un trascendental problema sanitario [10, 11].

Hoy en día, se pueden apreciar los efectos originados por el uso indiscriminado de los compuestos organoclorados al relacionarse la contaminación en los seres humanos con la posible aparición de problemas patológicos $[6,33,34]$. Las preocupaciones por esta contaminación se fundamentan al observarse la acu- mulación y la persistencia de los pesticidas organoclorados en la cadena trófica y, especialmente, en tejidos ricos de grasa de los organismos.

Los residuos organoclorados presentan para el hombre un riesgo debido a su toxicidad crónica por la ingestión continuada de pequeñísimas cantidades presentes en los alimentos [30]. Su peligro real se centra en su acción sobre sistemas enzimáticos [30], vitaminas y hormonas, así como en su actividad carcinogenética [14, 24, 29, 36, 38]. La presencia de residuos organoclorados en grasa humana es un buen índice para la evaluación del grado de exposición del hombre a los agentes de contaminación persistentes en el medio ambiente $[1,12,13] \mathrm{y}$, especialmente, en los alimentos consumidos $[3,7,10,19]$. En España, residuos de p,p'$\mathrm{DDE}, \mathrm{HCB}, \mathrm{g}-\mathrm{HCH}$ y aldrin han sido determinados en muestras de tejido adiposo por diversos autores [22, $27,28,32]$. En este contexto se realiza la presente investigación, que tiene como objetivo principal determinar pesticidas organoclorados en tejido adiposo mamario de mujeres residentes en la Provincia de Córdoba (España), además, de correlacionar las concentraciones encontradas en las muestras con datos respecto a hábitos alimentarios y edad de las donantes.

\footnotetext{
Recebido para publicação em 14/05/01. Aceito para publicação em 05/10/01.

2 Departamento de Tecnologia e Ciência dos Alimentos, Centro de Ciências Rurais, Universidade Federal de Santa Maria. Campus Universitário Camobi. Santa Maria - RS. CEP 97105-900 - Brasil.

${ }^{3}$ Departamento de Bromatología y Tecnología de Alimentos, Facultad de Veterinaria, Universidad de Córdoba, España.

* A quem a correspondência deve ser enviada.
} 


\section{2 - MATERIAL Y METODO}

\section{1 - Toma de muestras y datos de encuestas}

Se obtuvieron 123 muestras de tejido adiposo de glándulas mamarias femeninas. Las muestras fueron tomadas de donantes sometidas a intervenciones quirúrgicas realizadas en el Hospital Provincial de la Ciudad Sanitaria "Reina Sofia” de Córdoba (España), durante el período comprendido entre febrero de 1996 a julio de 1997. El 53,7\% de las donantes presentaron carcinoma y el $46,3 \%$ tuvieron alteraciones benignas en las mamas. Las muestras, de aproximadamente $1 \mathrm{~g}$ de tejido graso, debidamente identificadas se guardaron en recipientes de vidrio y fueron mantenidas en congelación a $-20^{\circ} \mathrm{C}$ hasta el momento de su análisis.

Para todas las muestras obtenidas se recopilaron datos referentes a la edad de las donantes, así como datos respecto al alimento más consumido habitualmente por cada una de ellas.

\section{2 - Patrones de residuos organoclorados}

Se usaron cuatro pesticidas organoclorados: aldrín, lindano $(\gamma-\mathrm{HCH})$, hexaclorobenceno $(\mathrm{HCB})$ y diclorodifenil dicloroetileno (p,p'-DDE).

El equipo utilizado para este estudio fue el siguiente: rotavapor, refrigerador con congelador vertical, balanza analitica, triturador y cromatógrafo de gases (CG) Hewlett-Packard modelo 5890, dotado de un detector de captura de electrones (ECD) con fuente radioactiva $\mathrm{Ni}^{63}$, conectado a un integrador Hewlett-Packard modelo 3396 serie II. Para la separación de los pesticidas organoclorados se usó una columna capilar HewlettPackard (HP-1) de sílice fundida (Crosslinked Methyl Silicone Gum), de $25 \mathrm{~m}$ de longitud, 0,2mm de diámetro interno y $0,33 \mu \mathrm{m}$ de grosor de fase estacionaria (Film Thickness). Se empleó helio como gas portador y argónmetano como gas de apoyo del detector a flujos de $2,3 \mathrm{~mL} / \mathrm{min}$ y $40 \mathrm{~mL} / \mathrm{min}$, respectivamente. Las temperaturas de operación fueron las siguientes: inyector $225^{\circ} \mathrm{C}$, detector $225^{\circ} \mathrm{C}$ y horno $55^{\circ} \mathrm{C}$ de temperatura inicial y $250^{\circ} \mathrm{C}$ de temperatura final.

La cristalería específica para laboratorio de análisis de pesticidas organoclorados y los frascos para las muestras fueron limpiados según la metodología de ANGULO et al. [2].

Se utilizaron los reactivos siguientes: n-hexano para cromatografia de Merck, sulfato de sodio anhidro de Panreac Química S.A. y florisil de 60 a 100mesh de Sigma, previamente activado a $150^{\circ} \mathrm{C}$ durante 12 horas y desactivado con la adición de $2 \%$ de agua bidestilada.

La extracción y la purificación de los pesticidas organoclorados se realizaron de acuerdo con la metodología de GARRIDO, JODRAL, POZO [18]: se pesan 0,3g de tejido graso, se adicionan $10 \mathrm{~mL}$ de $\mathrm{n}$-hexano y se trituran a $13.500 \mathrm{rpm}$ durante $3 \mathrm{~min}$. La muestra triturada se transfiere a la columna cromatográfica, a la que previamente se ha colocado un tapón de lana de vidrio y se ha rellenado con $15 \mathrm{~g}$ de florisil y un lecho de sulfato de sodio anhidro de $1 \mathrm{~cm}$. Cuando se introduce la muestra en la columna, se eluye con $100 \mathrm{~mL}$ de $n$-hexano para arrastrar los compuestos objeto de estudio. El eluato con los posibles residuos es pasado por un embudo que contiene sulfato de sodio anhidro sujetado con lana de vidrio y recolectado en un matraz esférico. El extracto es evaporado a sequedad con un rotavapor a vacío y reconstituido con $2 \mathrm{~mL}$ de $\mathrm{n}$-hexano, de los cuales $3 \mu \mathrm{L}$ son inyectados en el cromatógrafo de gases para el análisis cualitativo y cuantitativo. El primero se realizó comparando los tiempos de retención, y el segundo mediante la comparación del área bajo el pico de los pesticidas determinados contra aquellos obtenidos con los patrones correspondientes. Los residuos organoclorados identificados por cromatografia de gases son confirmados por espectrometría de masas. Para cada conjunto de muestras sometidas a extracción en idénticas condiciones y en el mismo período de tiempo, se realizó un blanco de columna con el fin de evitar errores en la identificación de los compuestos.

Para la valoración del método analítico se efectuó un estudio de adición de diferentes concentraciones $(0,008,0,01,0,02,0,04$ e $0,05 \mu \mathrm{g} / \mathrm{mL})$ de patrones con 5 repeticiones, lo que permitió precisar el porcentaje promedio de recuperación de los compuestos investigados, así como la varianza y la desviación típica de los resultados obtenidos (Tabla 1 ).

TABLA 1. Recuperación media y desviación típica de los compuestos en estudio*.

\begin{tabular}{cccc}
\hline Compuesto & Recuperación media (\%) & Desviación típica & Coeficiente variación (\%) \\
\hline HCB & 101,47 & 9,63 & 9,49 \\
$\gamma$-HCH & 88,47 & 11,86 & 13,40 \\
Aldrín & 97,16 & 16,85 & 17,34 \\
p,p'-DDE & 102,68 & 12,79 & 12,45 \\
\hline
\end{tabular}

* Datos publicados anteriormente [9].

\section{3 - Análisis estadistico}

En el proceso de validación del método analítico utilizado en la investigación, se realizaron pruebas estadísticas como la media, la desviación típica y el coeficiente de variación porcentual. Para los datos referentes a las concentraciones de los pesticidas organoclorados, se realizaron análisis estadísticos básicos, como la media, la desviación típica, los mínimos y máximos del total de muestras analizadas. El análisis de varianza se ha realizado para interpretar la relación existente entre las concentraciones de pesticidas organoclorados y los datos respecto a hábitos alimentarios y edad de las donantes, asi como, se ha empleado el coeficiente de correlación lineal simple para establecer la relación entre las concentraciones de pesticidas organoclorados y la edad de las donantes. Ambos tests han sido realizados a un nivel de confianza de 95\%, como mínimo. Para el análisis estadístico de los datos se ha empleado el programa informático "Statistica" versión 4.5. 


\section{3 - RESULTADOS Y DISCUSION}

Con el cuestionario sobre el alimento más consumido y la edad se obtuvieron los datos que se encuentran agrupados en la Tabla 2. La clase "alimentación variada" se refiere a las contestaciones siguientes: de todo, varios, fruta-verdura, fruta-legumbre, fruta-carne, fruta-verdura-potaje, pescado-fruta, carne-verdura, carneleche y legumbre-carne-pescado. Como puede verse, un $40 \%$ de las donantes consideraron las frutas el alimento más consumido. Respecto a la edad, las donantes tenían una edad media de 51 años, con una mínima de 15 y una máxima de 87 años.

TABLA 2. Alimento más consumido y edad media de las donantes.

\begin{tabular}{lrrr}
\hline Clases de alimentos & Porcentaje (n) & Edad media \\
\hline Leche & 3,25 & $(4)$ & 56,0 \\
Frutas & 40,65 & $(50)$ & 53,6 \\
Carnes & 1,63 & $(2)$ & 33,5 \\
Pescados & 2,44 & $(3)$ & 41,7 \\
Verduras & 4,88 & $(6)$ & 62,5 \\
Legumbres & 6,50 & $(8)$ & 40,9 \\
Guisos y potajes & 6,50 & $(8)$ & 42,0 \\
Alimentación variada & 34,15 & $(42)$ & 52,3 \\
Total & $100,00(123)$ & 51,5
\end{tabular}

Los resultados obtenidos en la investigación sobre los pesticidas organoclorados en las muestras analizadas se encuentran recogidos en la Tabla 3.

TABLA 3. Frecuencia de determinación, desviación típica y niveles de pesticidas organoclorados detectados en las muestras de tejido adiposo mamario.

\begin{tabular}{ccccccc}
\hline Compuestos & $\begin{array}{c}\text { Frecuencia de } \\
\text { Determinación } \\
(\%)\end{array}$ & $\begin{array}{c}\text { Valor Medio } \\
(\mu \mathrm{g} / \mathrm{g})\end{array}$ & $\begin{array}{c}\text { Desviación } \\
\text { Típica }\end{array}$ & $\begin{array}{c}\text { Límite de } \\
\text { Detección } \\
(\mu \mathrm{g} / \mathrm{mL})\end{array}$ & $\begin{array}{c}\text { Valor } \\
\text { Mínimo } \\
(\mu \mathrm{g} / \mathrm{g})\end{array}$ & $\begin{array}{c}\text { Valor } \\
\text { Máximo } \\
(\mu \mathrm{g} / \mathrm{g})\end{array}$ \\
\hline $\mathrm{HCB}$ & 99 & 0,235 & 0,224 & 0,0002 & $\mathrm{ND}$ & 1,294 \\
$\gamma$-HCH & 15 & 0,003 & 0,012 & 0,0006 & $\mathrm{ND}$ & 0,110 \\
Aldrín & 64 & 0,005 & 0,009 & 0,0004 & $\mathrm{ND}$ & 0,029 \\
p,p'-DDE & 100 & 1,848 & 2,192 & 0,0003 & 0,019 & 17,992 \\
\hline
\end{tabular}

$\mathrm{ND}=$ no detectado

Respecto a las frecuencias de determinaciones de los pesticidas organoclorados se observa que el p,p'-DDE fue identificado en todas las muestras analizadas. E1 $\mathrm{HCB}$, aldrin y $\gamma$-HCH presentaron frecuencias de 99, 64 y $15 \%$, respectivamente.

Cuanto a los valores medios encontrados en las muestras de tejido mamario se señala que el p,p'-DDE presenta el nivel medio más elevado, $1,848 \mu \mathrm{g} / \mathrm{g}$ de tejido graso. El resto de los pesticidas organoclorados fueron detectados a niveles medios de $0,235 \mu \mathrm{g} / \mathrm{g}$ para el $\mathrm{HCB}$, $0,005 \mathrm{mg} / \mathrm{g}$ para el aldrín $\mathrm{y}$, por último, $0,003 \mu \mathrm{g} / \mathrm{g}$ de tejido mamario para el $\gamma-\mathrm{HCH}$.
El p,p'-DDE fue identificado por COSTABEBER et al. [8], COSTABEBER, JODRAL, ANGULO [9], GÓMEZCATALÁN et al. [20], HERNÁNDEZ et al. [21], MARTI, PRATS, MAS [26], MOLINA [27] y PLANAS et al. [31] como el pesticida que se encuentra en concentraciones más elevadas en el tejido graso, por ser el último y más estable

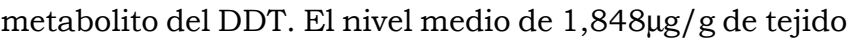
mamario presente en las muestras analizadas fue inferior, por un lado, al valor de $2,2 \mu \mathrm{g} / \mathrm{g}$ de tejido subcutáneo encontrado por KANJA et al. [23] y al valor de $2,5 \mu \mathrm{g} / \mathrm{g}$ de tejido adiposo encontrado por CORSOLINI et al. [5]. Por otro lado, fue considerablemente superior al nivel medio de $0,39 \mu \mathrm{g} / \mathrm{g}$ de tejido detectado por GALLELLI, MANGINI, GERBINO [17] y al de $1,19 \mu \mathrm{g} / \mathrm{g}$ tejido adiposo determinado por DUARTE-DAVIDSON, WILSON, JONES [13]. Dichas diferencias pueden ser debido al diferente grado de contaminación en los países donde fueran recogidas las muestras.

HERRERA et al. [22] investigaron los niveles de g$\mathrm{HCH}$, aldrín y p,p'-DDE en 40 muestras de grasa humana obtenidas en la Provincia de Madrid. Las concentraciones medias de los compuestos detectados fueron de 0,016, 0,0003 y 2,668 $\mu \mathrm{g} / \mathrm{g}$ de tejido adiposo, respectivamente. Los niveles medios detectados en esta investigación (Tabla 3) son inferiores a los encontrados por HERRERA et al. [22], excepto en el caso del aldrín. Se pudo observar, que los niveles de p,p'-DDE han descendido un $30 \%$ durante el periodo de tiempo que separan los dos estudios.

POZO et al. [32] detectaron $1,007 \mu \mathrm{g} / \mathrm{g}$ de tejido adiposo de $\mathrm{HCB}$ en grasa humana de la Provincia de Madrid. Es importante señalar que en el presente estudio se ha encontrado el HCB a un nivel medio de $0,235 \mu \mathrm{g} / \mathrm{g}$ de tejido, lo que significa una reducción de un $76 \%$ comparado al nivel detectado por POZO et al. [32] para dicho compuesto desde hace 23 años.

MOLINA [27] detecta cantidades importantes de g$\mathrm{HCH}$, aldrin, p,p'-DDE y $\mathrm{HCB}$ en muestras de tejido adiposo humano de la Región de Murcia, así obtiene concentraciones de $0,658 \mu \mathrm{g} / \mathrm{g}$ de tejido de $\mathrm{g}-\mathrm{HCH}$, $1,26 \mu \mathrm{g} / \mathrm{g}$ de tejido de aldrín, 4,03 $\mu \mathrm{g} / \mathrm{g}$ de tejido de p,p'DDE y $1,07 \mu \mathrm{g} / \mathrm{g}$ de tejido de HCB. Resultados semejantes han sido encontrados por MOLINA et al. [28] con excepción del HCB que no ha sido objeto de estudio. Los valores encontrados por los autores son superiores a los encontrados para estos compuestos en el presente trabajo.

Asimismo, CAMPS et al. [4], FERRER et al. [15, 16], GÓMEZ-CATALÁN et al. [20], HERNÁNDEZ et al. [21], MARTI, PRATI, MAS [26], PLANAS et al. [31] y TOFIGUERAS et al. [35] realizaron determinaciones de uno o más pesticidas organoclorados que también fueron objeto de estudio en esta investigación, pero los niveles detectados por ellos no son comparables, puesto que los determinaron en base grasa, mientras que el presente se realizó en muestras enteras.

Respecto a la edad de las donantes y los niveles de residuos organoclorados, se observó una correlación positiva ( $\mathrm{p} \leq 0,001)$ para los compuestos $\mathrm{HCB}$, aldrin y $\mathrm{p}, \mathrm{p}$ - 

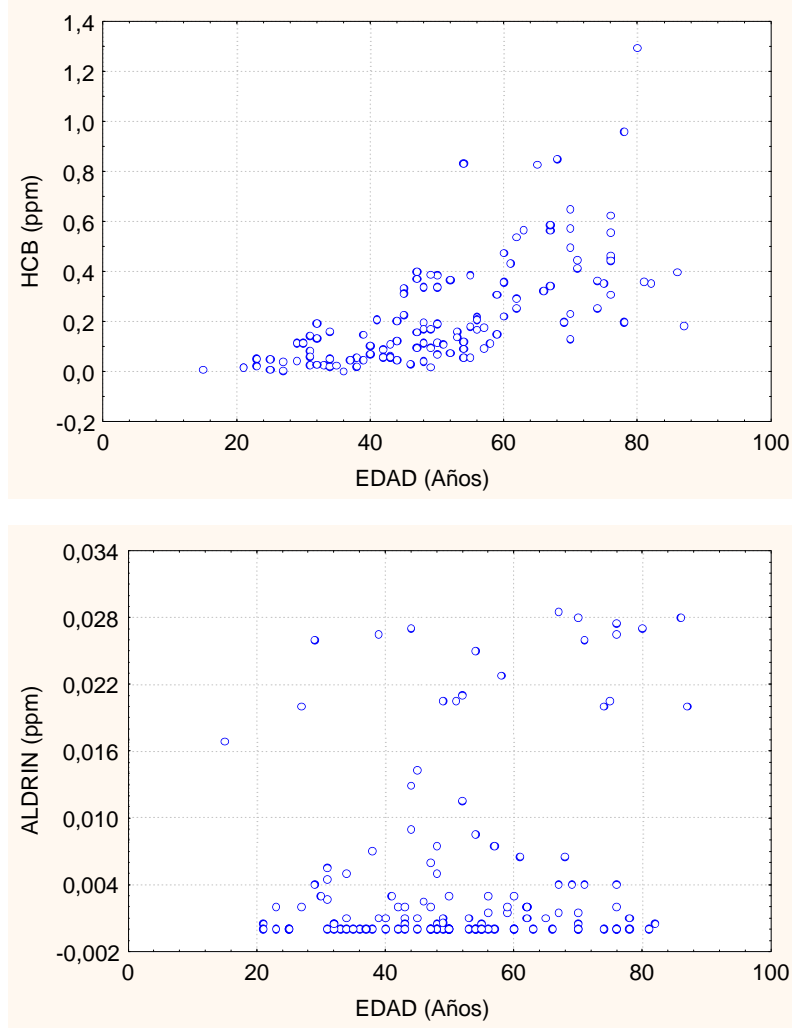
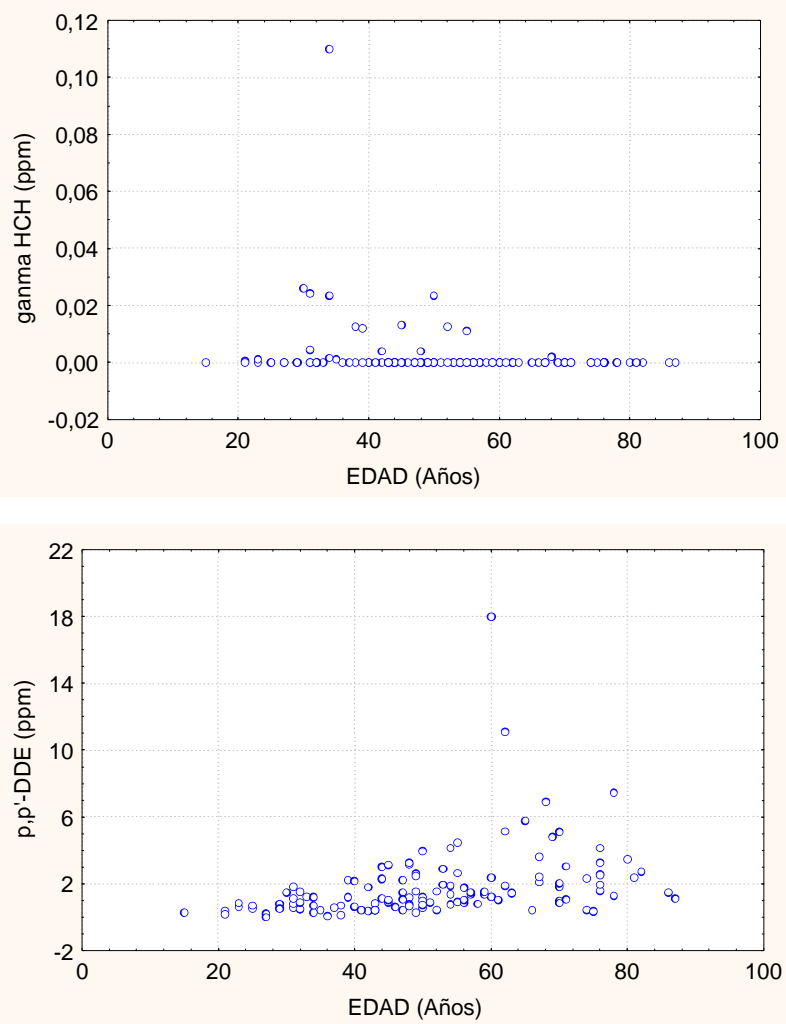

FIGURA 1. Concentración de los pesticidas organoclorados según la edad de las donantes

DDE indicando el incremento de las concentraciones de residuos de pesticidas con el aumento de la edad de las donantes (Figura 1). Los resultados concuerdan con los obtenidos en investigaciones anteriores [4, 16, 25]. Sin embargo, para el $\gamma$-HCH se ha observado una correlación no significativa entre los niveles en el tejido y la edad, posiblemente debido al hecho que pocas muestras presentaban este compuesto. Tampoco MOLINA [27] ha establecido correlación significativa entre niveles de $\gamma$ $\mathrm{HCH}$ y la edad de los donantes.

Se señala que los compuestos $\mathrm{HCH}$ (con más de $90 \%$ de $\gamma$-HCH) y HCB han sido prohibidos en España en 1986 (Orden Ministerial de 28 de febrero), mientras que el DDT y el aldrín han sido prohibidos en 1991 (Orden Ministerial de 1 de febrero).

Respecto a los hábitos alimentarios y los valores de pesticidas organoclorados, la Tabla 4 refleja las concentraciones de los compuestos detectados en las muestras de tejido adiposo mamario según la indicación de las donantes respecto al alimento más consumido por cada una de ellas.

El análisis de varianza entre los datos de los alimentos más consumidos y las concentraciones de los compuestos investigados mostró una relación estadística no significativa ( $p>0,05$ para todos los casos). Tampoco, se ha establecido una relación estadísticamente significativa cuando se ha clasificado los datos en tres grupos: a) alimentos ricos en gordura (leite, carne y pescado), b) alimentos pobres en gordura (fruta, verdura y legumbre) y, c) alimentación variada. Respecto a los hábitos alimentares de estas donantes, la mayoria (75\%) consideraron las frutas y la alimentación variada los alimentos más consumidos. Así, la distribución desigual de las muestras puede ser la causa de la ausencia de correlación entre las concentraciones detectadas y los hábitos alimentares de las mujeres.

TABLA 4. Concentraciones de los pesticidas organoclorados según los alimentos más consumidos por las donantes.

\begin{tabular}{|c|c|c|c|c|c|c|c|c|}
\hline Compuestos & Leche & Frutas & Carnes & Pescados & Verduras & Legumbres & $\begin{array}{r}\text { Alimentación } \\
\text { variada }\end{array}$ & $\begin{array}{r}\text { Guisos y } \\
\text { potajes }\end{array}$ \\
\hline$\overline{\mathrm{HCB}}$ & 0,339 & 0,258 & 0,078 & 0,138 & 0,374 & 0,156 & 0,214 & $\overline{0,196}$ \\
\hline$\gamma-\mathrm{HCH}$ & 0,001 & 0,002 & 0,001 & ND & 0,018 & 0,003 & 0,002 & 0,002 \\
\hline Aldrín & 0,007 & 0,006 & 0,001 & 0,005 & 0,006 & 0,002 & 0,004 & 0,013 \\
\hline p,p-DDE & 2,774 & 2,119 & 0,641 & 1,281 & 3,273 & 0,994 & 1,567 & 1,473 \\
\hline
\end{tabular}

$\mathrm{ND}=$ No detectado

Asimismo, se señala que las mayores concentraciones de los compuestos HCB, $\gamma$-HCH y p,p'-DDE fueron encontradas en las mujeres que consideraron las verduras el alimento más consumido, mientras que las mayores concentraciones de aldrín fueron encontradas en las que consideraron los guisos y potajes el alimento más consumido. En lo que se refiere al p,p'-DDE y al $\mathrm{HCB}$, tal observación puede ser debido a la mayor edad media (62,5 años) que poseen las donantes que 
consideraron las verduras el alimento más consumido (Figura 1). Por otro lado, las concentraciones más bajas de los compuestos HCB, aldrín y p,p'-DDE fueron encontradas en las mujeres que consideraron las carnes el alimento más consumido, mientras que el $\gamma-\mathrm{HCH}$ no fue detectado en el tejido graso mamario de las donantes que indicaron el pescado como el alimento más consumido habitualmente. En el caso de consumo de carnes y bajas concentraciones de compuestos, se señala que las donantes eran mujeres más jóvenes, con una edad media de 33,5 años.

Según LUDWICKI y GÓRALCZYK [25] la mayor presencia de p,p'-DDE en el tejido adiposo tiene su origen principalmente en la dieta y, en menor proporción, del metabolismo del DDT en el hombre. En este sentido WALISZEWSKI et al. [37] atribuyen los valores elevados de p,p'-DDE en el tejido adiposo humano a la contaminación presente en los alimentos ingeridos de origen animal, donde el DDT fue metabolizado previamente a DDE. En la presente investigación el p,p'-DDE ha sido detectado en concentraciones más altas en las muestras de las mujeres que consideraron las verduras como el alimento más consumido, posiblemente por el amplio uso que ha tenido el DDT en la agricultura. Sin embargo, la correlación establecida entre el nivel de p,p'-DDE y el consumo de verduras ha sido estadísticamente no significativa.

\section{4 - CONCLUSIONES}

Los resultados obtenidos en el presente estudio indicaron una correlación no significativa entre la dieta de las donantes y los niveles de los compuestos encontrados en el tejido mamario. Con el aumento de la edad de las donantes se produce un incremento de los niveles de residuos organoclorados en el tejido mamario, a excepción del $\gamma$-HCH. Estos resultados sugieren que la edad ha sido el factor que mejor se correlaciona con las concentraciones de organoclorados detectadas en el tejido adiposo, mientras que la dieta, en la forma evaluada en el presente estudio, no ha representado el factor determinante de la carga corporal de estas mujeres.

Desde nuestro punto de vista, la obtención de datos fiables sobre la importancia de los hábitos alimentarios respecto a la carga corporal de residuos organoclorados es muy compleja y requiere estudios más detallados sobre el tipo y la cantidad de los alimentos consumidos. Asimismo, sería conveniente conocer, mediante estudios preliminares, la contaminación por residuos organoclorados presente en los alimentos.

\section{5 - REFERENCIAS BIBLIOGRAFIAS}

[1] ALAWI, M.A.; TAMIMI, S.; JAGHABIR, M. Storage of organochlorine pesticides in human adipose tissues of Jordanian males and females. Chemosphere, v. 38, n. 12, p. 2865-2873, 1999.

[2] ANGUlO, R.; COSTABEBER, I.; GALlEGO, M.C.; SERRANO, S.; JODRAL, M.. Clean-up destillation: critical points in the organochlorine residue analysis. 1 ST European Pesticide Residue Worshop. p. 59. AlkmaarNetherlands. June 10-12, 1996.
[3] BENTABOL, A.; GARRIDO, M.D.; MARTINEZ, P.; ANGULO, R.; ACOSTA, I.; GALLEGO, M.D., JODRAL, M. Evolución de pesticidas organoclorados en quesos de cabra madurados. I Congreso Internacional de Tecnologia y Calidad Alimentaria: Residuos Fitosanitarios en Alimentos. p. 249254. Logroño (La Rioja). 2630 de abril de 1995.

[4] CAMPS, M.; PLANAS, J.; GOMEZ-CATALÁN, J.; SABROSO, M.; TO-FIGUERAS, J.; CORBELLA, J. Organochlorine residues in human adipose tissue in Spain: Study of an agrarian area. Bulletin of Environmental Contamination and Toxicology, v. 42, p. 195-201, 1989.

[5] CORSOLINI, S.; FOCARDI, S.; KANNAN, K.; TABANE, S.; TATSUKAWA, R. IsomerSpecific Analysis of Polychlorinated Biphenyls and 2, 3, 7, 8Tetrachlorodibenzopdioxin Equivalents (TEQs) in Red Fox and Human Adipose Tissue from Central Italy. Archives of Environmental Contamination and Toxicology, v. 29, p. 6168, 1995.

[6] COSTABEBER, I. Resíduos organoclorados persistentes en grasa mamaria y su relación con los hábitos alimentarios: repercusiones sanitarias. Córdoba (España), 1999. 315p. Tesis Doctoral - Departamento de Bromatología y Tecnologia de Alimentos, Facultad de Veterinaria, Universidad de Córdoba.

[7] COSTABEBER, I.; TRINDADE, R.; FRIES, L.M. Residuos de DDE, HCB, heptacloro epóxido y lindano en elche UHT comercializada en Santa Maria, RS. ILE, v. 259, p. 4247, 2000a.

[8] COSTABEBER, I.; JODRAL, M.; ANGULO, R.; VALERA, M.; MOLINA, A. Evaluación de niveles de residuos organoclorados en tejido adiposo de residentes en la provincia de Córdoba-España. Revista Internacional de Contaminación Ambiental, v. 16, n. 3, p. 119-126, 2000b.

[9] COSTABEBER, I.; JODRAL, M.; ANGULO, R. Detecção de pesticidas organoclorados e bifenilos policlorados em amostras biológicas. Pesticidas: Revista de Ecotoxicologia e Meio Ambiente, v. 10, p. 1-12, 2000c.

[10] COSTABEBER, I.; TRINDADE, R.; FRIES, L.M. Niveles de plaguicidas organoclorados en leche bovina. Alimentaria, v. 319, p. 127-129, 2001.

[11] DAGHER, S.M.; TALHOUK, R.S.; NASRALIAH, S.S.; TANNOUS, R.I.; MROUEH, S.M. Relationship of dietary intake to DDE residues in breast milk of nursing mothers in Beirut. Food Additives and Contaminats, v. 16, n. 7, p. 307-312, 1999.

[12] DEWAILly, E.; MULVAD, G.; PEDERSEN, H.S.; AYOTTE, P.; DEMERS, A.; WEBER, J.P.; HANSEN, J.C. Concentration of organochlorines in human brain, liver, and adipose tissue autopsy samples from Greenland. Environmental Health Perspectives, v. 107, n. 10, p. 823-828, 1999.

[13] DUARTEDAVIDSON, R.; WILSON, S.C.; JONES, K.C. PCB's and other organochlorines in human tissues samples from the welsh population: Iadipose. Environmental Pollution, v. 84, p. 6977, 1994.

[14] FALCK, F.J.; RICCI, A.J.; WOLFF, M.S.; GODBOLD, J.; DECKERS, P. Pesticides and polychlorinated biphenyl residues in human breast lipids and their relation to breast cancer. Archives of Environmental Health, v. 47, n. 2, p. 143-146, 1992.

[15] FERRER, A.; BONA, M.A.; CASTELLANO, M.; BRUNET, M.; TO-FIGUERAS. Estudio de la presencia de HCB en tejido adiposo en la población de Zaragoza. $1^{\mathbf{a}}$ Jornadas Nacionales sobre Hexaclorobenceno, Barcelona (España), p. 131-139, 1990. 
[16] FERRER, A.; BONA, M.A.; CASTELLANO, M.; TO-FIGUERAS, J.; BRUNET, M. Organochlorine residues in human adipose tissue of the population of Zaragoza (Spain). Bulletin of Environmental Contamination and Toxicology, v. 48, p. 561-566, 1992.

[17] GALLELLI, G.; MANGINI, S.; GERBINO, C. Organochlorine residues in human adipose and hepatic tissues from autopsy sources in northern Italy. Journal of Toxicology and Environmental Health, v. 46, p. 293-300, 1995.

[18] GARRIDO FERNANDEZ, M.D.; JODRAL VILLAREJO, M.L.; POZO LORA, R. Bifenilos policlorados en leches esterilizadas españolas y estudio experimental del efecto de la temperatura sobre estos compuestos. $\mathbf{N}+\mathbf{D}$, n. 0, p. 3540, 1992.

[19] GARRIDO FERNANDEZ, M.D.; JODRAL VILLAREJO, M.L.; POZO LORA, R. Organochlorine pesticides in Spanish sterilized milk and associated health risks. Journal of Food Protection. v. 57, n. 3, p. 249-252, 1994.

[20] GOMEZ-CATALAN, J.; PLANAS, J.; TO-FIGUERAS, J.; CAMPS, M.; CORBELLA, J. Organochlorine pesticide residues in the population of Catalonia (Spain). Bulletin of Environmental Contamination and Toxicology, v. 51, p. 160-164, 1993.

[21] HERNANDEZ, L.M.; FERNANDEZ, M.A.; JIMENEZ, B.; GONZALEZ, M.J. Organoclorine insecticides and polychlorinated biphenyls in human adipose tissue in Madrid (Spain). Toxicological and Environmental Chemistry, v. 37, p. 125-132, 1992.

[22] HERRERA MARTEACHE, A.; POLO VILLAR, L.M.; JODRAL VILLAREJO, M.; POLO VILLAR, G.; MALLOL, J.; POZO LORA, R. Residuos de plaguicidas organoclorados en grasa humana en España. Revista de Sanidad y Higiene Pública, v. 12, p. 120, 1978.

[23] KANJA, L.W.; SKAARE, J.U.; OJWANG, S.B.O.; MAITAI, C.K. A comparison of organochlorine pesticides residues in maternal adipose tissue, maternal blood, cord blood and human milk from mother/infant pairs. Archives of Environmental Contamination and Toxicology, v. 22, p. 2124, 1992.

[24] KRIEGER, N.; WOLFF, M.S.; HIATT, R.A.; RIVERA, M.; VOLGELMAN, J.; ORENTREICH, N. Breast cancer and serun organochlorines: a prospective study among white, black, and asian women. Journal of the National Cancer Institute, v. 86, n. 8, p. 589599, 1994.

[25] LUDWICKI, J.K.; GORALCZYK, K. Organochlorine pesticides and PCBs in human adipose tissues in Poland. Bulletin of Environmental Contamination and Toxicology, v. 52, p. 400-403, 1994.

[26] MARTI, J.B.; PRATS, D.; MAS, M.E. Contaminación por organoclorados en tejido adiposo humano. $\mathbf{1}^{\mathbf{a}}$ Jornadas Nacionales sobre Hexaclorobenceno. Barcelona (España), p. 141-147, 1990.

[27] MOLINA, C. Residuos de insecticidas organoclorados en tejidos grasos de la población no expuesta de la Región de Murcia. Múrcia (España), 1994. Tesis Doctoral Facultad de Medicina, Universidad de Murcia.

[28] MOLINA, C.; LUNA, A.; CAMARA, M.A.; NAVARRO GARCIA, S.; BARBA, A. Residuos de insecticidas organoclorados en poblacion no expuesta de la region de Murcia. I Congreso Internacional de Tecnologia y Calidad Ali- mentarias: Residuos Fitosanitarios en Alimentos. p. 277-281. La Rioja (España), 26-30 de abril de 1995.

[29] MUSSALO-RAUHAMAA, H.; HASANEN, E.; PYYSALO, H.; ANTERVO, K.; KAUPILLA, R.; PANTZAR, P. Occurrence of beta-hexachlorocyclohexane in breast cancer patienst. Journal of the American Cancer Society, v. 66, p. 21242125, 1990.

[30] ORGANIZACION MUNDIAL DE LA SALUD (OMS). Consecuencias sanitarias del empleo de plaguicidas en la agricultura. Ginebra, 1992.

[31] PLANAS, J.; GOMEZ-CATALÁN, J.; TO-FIGUERAS, J.; SABROSO, M.; CAMPS, M.; CORBELLA, J. Residuos de hexaclorobenceno en el tejido adiposo de la población de Cataluña (1986-87). Primeras Jornadas Nacionales Hexaclorobenceno, p. 149-159. Barcelona (España), 1990.

[32] POZO LORA, R.; HERRERA MARTEACHE, A.; POLO VILLAR, L.M.; JODRAL VILLAREJO, M.; MALLOL ESCOBAR, J.; POLO VILLAR, G. Presencia del fungicida sintético hexaclorobenceno (HCB) en tejido adiposo humano en España. Revista de Sanidad y Higiene Pública, v. 52, p. $11451150,1978$.

[33] STELLMAN, S.D.; DJORDJEVIC, M.V.; BRITTON, J.A.; MUSCAT, J.E.; CITRON, M.L.; KEMENY, M.; BUSCH, E.; GONG, L. Breast cancer risk in relation to adipose concentrations of organochlorine pesticides and polychlorinated biphenyls in Long Island, New York. Cancer Epidemiology Biomarkers \& Prevention, v. 9, n. 11, p. 1241-1249, 2000.

[34] SUWALSKY, M.; RODRIGUEZ, C.; VILLENA, F.; AGUILLAR, F.; SOTOMAYOR, C.P. The pesticide hexachlorobenzene induces alterations in the human erythrocyte membrane. Pesticide Biochemistry and Physiology, v. 65, n. 3, 205-214, 1999.

[35] TO-FIGUERAS, J.; RODAMILANS, M.; GÓMEZ, J.; CORBELLÁ, J. Hexachlorobenzene in the general population of Barcelona (Spain). In: Hexachlorobenzene: Proceedings of an International Symposium (IARC Scientific Publications N. 77), 1986, p. 147-148.

[36] UNGER, M.; KIAER, H.; BLICHERT-TOFT, M.; OLSEN, J.; CLAUSEN, J. Organochlorine compounds in human breast fat from deceased women with and without cancer and in biopsy material from newly diagnosed patients undergoing breast surgery. Environmental Research, v. 34, p. 24-28, 1984.

[37] WALISZEWSKI, S.M.; PARDIO SEDAS, V.T.; CHANTIRI PEREZ, J.N.; INFANZON RUIZ, R.M.; RIVERA, J. Evaluación de los niveles de DDT y $\mathrm{HCH}$ en el tejido adiposo de algunas personas fallecidas en el Estado de Veracruz, México. Revista Internacional de Contaminación Ambiental, v. 11, n. 2, p. 87-93, 1995.

[38] WOLFF, M.S.; TONIOLO, P.G.; LEE, E.W.; RIVERA, M.; DUBIN, N. Blood levels of organochlorine residues and risk of breast cancer. Journal of the National Cancer Institute, v. 85, n. 8, p. 648-652, 1993.

\section{6 - AGRADECIMIENTOS}

Se agradece al Conselho Nacional de Desenvolvimento Científico e Tecnológico (CNPq) por la concesión de la beca de Recém-Doutor (RD) al primer autor. 